\title{
Uma escola para homem rural: a cultura popular, os cam- poneses e o movimento de educação de base (1960-1964)
}

Claudia Moraes de Souza

Universidade Estadual Paulista

\section{Resumo}

Nos idos dos anos 1960, a intervenção sobre a cultura popular tornou-se um suposto da ação política de agentes modernizadores da sociedade brasileira. Por meio da Conferência Nacional dos Bispos do Brasil (CNBB), a Igreja Católica elaborou um projeto educacional de dimensão nacional, articulando suas emissoras de rádio no território brasileiro aos centros de educação radiofônica rural e criando, em 1961, o Movimento de Educação de Base (MEB). Os pressupostos teóricos e filosóficos do Movimento transcendiam as questões do aprendizado formal e pautavam-se por estratégias de ação da Igreja sobre os problemas de crescimento econômico e desenvolvimento social das regiões pobres brasileiras. 0 artigo em questão versa sobre o camponês que participou do MEB e suas experiências escolares, avaliando os preceitos de educação rural, educação cívica e alfabetização de adultos propostos na ação dos agentes e das instituições modernizadoras do campo brasileiro. Analisamos os processos de assimilação e resistência do camponês aos princípios e projetos modernizantes externos à sua cultura. Novos ritmos de tempo, novas representações e novos significados foram introduzidos pela escola sobre práticas culturais seculares do campesinato brasileiro. No MEB, tal fenômeno resultou tanto na assimilação dos novos estímulos trazidos pela escola, quanto na insurreição de costumes e hábitos interligados às funções ritualísticas e costumeiras do indivíduo e/ou da comunidade rural.

\section{Palavras-chave}

Educação rural - Camponês - Cultura popular. 


\section{A school for rural people: popular culture, peasants and the basic education movement (1960-1964)}

Claudia Moraes de Souza

São Paulo State University

\begin{abstract}
In the 1960s, the intervention on popular culture became an assumption of the political action of the modernizing agents of Brazilian society. Through the National Conference of Bishops of Brazil (CNBB), the Catholic Church developed a nationwide educational project, linking its radio stations in Brazil to the centers of radio education, and in 1961 it created the Basic Education Movement (MEB). The theoretical and philosophical assumptions of the movement transcended the issues of formal learning and were based on strategies of action of the Catholic Church on issues of economic growth and social development of the poor regions of Brazil. This article is about the peasants who participated in the MEB and their school experiences. It evaluates the precepts of rural education, civic education and adult literacy proposed in the action of the agents and the modernizing institutions of the Brazilian countryside. I have analyzed the processes of assimilation and resistance of the peasants to the modernizing principles and projects outside their culture. New rhythms of time, representations and meanings were introduced by schools into the secular cultural practices of the Brazilian peasantry. In the MEB, this phenomenon resulted both in the assimilation of new stimuli brought by the school, and in the insurrection of customs and habits connected to the ritualistic and customary functions of the individual and / or rural community.
\end{abstract}

\section{Keywords}

Rural education - Peasant - Popular culture. 
Este artigo trata da ação do Movimento de Educação de Base (MEB) em Pernambuco, nos idos de 1960 a 1964. Nosso objetivo foi investigar as relações culturais e políticas entre os mediadores do MEB - organismo liderado pela Conferência Nacional dos Bispos do Brasil (CNBB) - e os camponeses da zona da mata pernambucana envolvidos naquele que ainda hoje é considerado o maior projeto de educação rural do Brasil.

Partimos da ideia de que a chegada da escola nas comunidades camponesas revela a sobreposição de normas e diretrizes reguladoras, imbuídas da cultura moderna, a um conjunto de práticas sociais próprias da cultura do lugar. Assim, o MEB, como movimento educacional, ofertou à população rural uma série de práticas voltadas à educação e à alfabetização, e orientadas pelo conceito de educação de base ${ }^{1}$, o qual foi largamente difundido em nível internacional pela Organização das Nações Unidas para a Educação, a Ciência e a Cultura (UNESCO). 0 cerne do artigo é recuperar o contexto em que camponeses e trabalhadores rurais conviveram com agentes educacionais, em uma experiência reveladora do confronto de diferentes ideias postas na cultura camponesa e nos mediadores educacionais.

0 MEB defendia a educação de base como forma de modernização, emancipação e promoção das comunidades e do homem rural, pretendendo renovar o velho contexto do mandonismo local e da política do favor e substituí-lo por um contexto de desenvolvimento comunitário, cooperacionista, próprio das concepções racionalistas modernizadoras do populismo católico ${ }^{2}$. Por outro lado, o

1- A educação de base (EB) foi definida na documentação oficial da UNESCO, nos anos 1950. A proposta consistia em levar conhecimentos às comunidades carentes por meio do processo educacional, favorecendo a aquisição de mecanismos para a ação comunitária e mudanças de atitudes e comportamentos sociais. 0 conceito de educação de base envolvia, além da alfabetização, o desenvolvimento de noções de saúde e higiene, educação moral e cívica, e educação para o trabalho.

2- Para Canclini (2000), o popular é construído historicamente na modernidade a partir de três correntes: 0 folclorismo, a indústria cultural e o populismo. 0 populismo como ideologia concebeu o popular como objeto puro, realizando a fragmentação das culturas e propondo a modernização como forma de superação do tradicionalismo que caracteriza o popular. homem rural, imbuído de costumes e tradições da cultura popular, resiste e/ou assimila elementos extrínsecos à sua cultura de acordo com interesses comunitários e de forte fundo econômico e político.

\section{A chegada da escola: sobre O MEB} e suas origens

0 MEB articulava diversos sistemas radioeducativos constituídos por uma rede de núcleos organizados para a recepção de programas educacionais especialmente elaborados para a educação e a alfabetização de adultos em áreas rurais. Em âmbito nacional, entre 1961 e 1965³, formava-se uma rede de emissoras subordinadas a uma estrutura organizativa hierarquizada. De uma ampla base, composta pelas unidades escolares radiofônicas, afunilava-se para uma direção nacional, assumida por representantes diretos da CNBB e do MEC, que coordenavam a atuação dos organismos regionais e locais. Inicialmente, em 1961, o MEB contou com programas em dez emissoras, evoluindo num processo crescente e atingindo, ao final de 1965, o número de 29 emissoras interligadas, responsáveis pela transmissão diária dos programas educativos elaborados pelas equipes locais de quatorze Estados brasileiros.

Munido de uma estrutura física garantida pela rede de emissoras católicas, o MEB articulou objetivos e finalidades educacionais a uma lógica organizacional e técnica. Isso permitiu o funcionamento contínuo de diferentes sistemas responsáveis pela comunicação entre o aluno/ouvinte e o professor/locutor, gerando, a partir daí, um processo educacional que conectava emissores e receptores com o intuito de transcender a mera transmissão de conhecimentos e irradiar um conjunto de práticas cole-

3 - Entre 1961 e 1965, o MEB atingiu o auge em número de emissoras vinculadas ao programa, o que não implica que os sistemas tenham funcionado apenas nesse intervalo temporal. Mesmo após o Golpe e a instalação da ditadura civil-militar, o MEB continuou operando em moldes diferenciados, persistindo ligado à CNBB e atuante no campo da educação popular como uma organização não governamental até os dias atuais. 
tivas que tivessem efeitos na vida cotidiana do trabalhador rural.

Para o MEB, era preciso ir além da mera extensão de conhecimentos e construir uma comunicação entre o aluno e os agentes educacionais.

[...] 0 nosso drama, não é só alfabetizar. Junto a isso, há urgência de muito mais. Há urgência de se abrirem aos nossos camponeses, operários e suas famílias as riquezas da educação de base, fundamental educação que chamaríamos de cultura popular, a qual tem a força de fazer o homem despertar para seus próprios problemas, encontrar suas soluções, defender sua saúde, manter boas relações com seus semelhantes, andar com seus próprios pés, decidir dos seus destinos, buscarem sua elevação cívica, moral, econômica, social e espiritual. Evidentemente não falamos do tipo de escola tradicional com professor para um grupo de alunos. Seria impossível dessa forma, hoje, no Brasil, se atingir milhões de analfabetos. Vamos apelar para o rádio, para as escolas radiofônicas. (MEB/NACIONAL, s/d.c)

Ao longo de suas atividades, o MEB demonstrou-se preocupado com uma ação pedagógica diferenciada em relação às campanhas alfabetizadoras das décadas de 1940 e $1950^{4}$, bem como com a focalização de situações e dificuldades específicas dos territórios atingidos pelo programa. Os pressupostos teóricos do Movimento transcendiam as questões do aprendizado formal, pautando-se por estratégias de ação da Igreja sobre problemas da sociedade brasileira no contexto dos anos 1960, em que o movimento de ideias da sociedade concebia a ação cultural como uma ação polí-

4 - Em seu discurso oficial, o MEB demonstrou preocupações com 0 intervencionismo em comunidades rurais, propondo ações educacionais que evitassem o paternalismo sobre populações. Na documentação de 1961, que remonta ao processo inaugural do MEB, encontramos críticas a programas alfabetizadores assistencialistas dos anos 1950. tica que articulava alfabetização, educação cívica e a educação rural à vida da comunidade.

[...] No funcionamento do sistema radioeducativo é essencial a adequação da programação à realidade das comunidades a que ela se dirige, por isso o trabalho do MEB exige o conhecimento prévio dos problemas, necessidades e recursos existentes nas áreas a serem atingidas, como fase necessária para fundamentação do trabalho posterior, esse estudo, que antecede a criação das escolas nas comunidades, é continuamente atualizado [...]. Essa motivação é sempre realizada no sentido de fazer a população local encarar sua educação como algo possivel e necessário para a verdadeira promoção de suas comunidades. (MEB/ NACIONAL, 1963)

A ideia de promoção da comunidade no universo mental do MEB associava-se aos preceitos da educação de base, segundo os quais a comunidade deve promover autonomamente seu desenvolvimento, "numa perspectiva de autopromoção que leve à transformação decisiva da mentalidade e das estruturas" (MEB/NACIONAL, s/d.b). Essas ideias que informavam as ações iniciais do Movimento na fase de radicação da escola, quando levadas a campo, esbarravam na realidade local. Devemos lembrar a complexidade de relações sociais presentes no território em que o projeto atuou majoritariamente: o Nordeste rural brasileiro, lugar que reunia grandes propriedades rurais, usinas de cana, lideranças políticas locais, trabalhadores agregados, pequenos sitiantes etc.

\section{Culturas que se encontram: os} camponeses, o rádio e a educação de base

A educação de base do MEB tinha por objetivo tornar-se o veículo de comunicação entre as necessidades das comunidades e o desnivel cultural imposto pelas condições do desenvolvimento. 
[...] A Educação de Base é de real necessidade porque vai diminuindo a ignorância e o analfabetismo de nosso povo, transformando-o social e economicamente. A escola radiofônica vai colaborar no desenvolvimento do povo, ajudando-o a viver e a trabalhar melhor, devido à capacidade formidável do rádio de atingir um maior número de pessoas adultas, dando conhecimentos necessários e práticos. (MEB/PERNAMBUCO, 1961)

Na comunidade rural, a educação de base consistiria em alfabetizar e atuar junto aos indivíduos, visando a mudanças de atitudes e comportamentos socioculturais. Nos lugares em que o MEB atuou, foram desenvolvidos trabalhos nas seguintes áreas: saúde, alimentação e higiene; habitação; convívio na família; relações sociais em casa e na vizinhança; relações de trabalho; organização religiosa e política das comunidades.

Para o MEB, a escola de rádio e sua ação poderiam integrar os indivíduos aos códigos da cultura universal e, mais do que isso, integrar o indivíduo e a comunidade rural a um conjunto social direcionado ao desenvolvimento, o que, sob a ótica da Igreja Católica, exigia transformações radicais de padrões e comportamentos.

As concepções da escola radiofônica não se distanciavam dos papéis vividos pela escola na sociedade moderna. Segundo Pierre Bourdieu (1982), tais papéis se definem por propiciar aos indivíduos um corpo comum de categorias de pensamento que tornam possível a comunicação, assumindo funções de integração e de inserção social. A escola, nessa perspectiva, responsabiliza-se pelo cultivo de códigos, percepções, ações e pensamentos necessários ao homem apto à vida social ${ }^{5}$ e, em dadas sociedades, exerce funções de definir e hierarquizar o cursus da cultura adquirida, submetendo-a a um programa e a transmissões metódicas de conteúdos.

5 - Bourdieu (1982) desenvolve a ideia de homem cultivado como aquele que recebe os códigos para a vida social por meio da cultura.
De acordo com esse raciocínio, a escola moderna tornou-se responsável pela integração cultural de indivíduos, os quais se integram por meio da família, da escola e da classe social. Dessa forma, a escola é histórica, gerida por dilemas e questões de sua época, estruturada e reestruturada, sucessivamente, por continuidades e rupturas que asseguram a comunicação de diferentes elementos de múltiplos campos culturais.

Naquele momento, o MEB, buscava ratificar funções da escola que integrassem o homem rural a códigos e signos sociais articulados a um modelo de desenvolvimento econômico e social preestabelecido. Optou-se por um conjunto de intervenções necessárias junto a hábitos, comportamentos e valores, visando à mudança de atitudes em prol da aceitação de normas e regras ditadas por um campo cultural distinto do campo cultural do camponês. Assim, o camponês integrado na família e na classe deveria também se integrar culturalmente à escola e a uma cultura outra, dita moderna.

À medida que as escolas se estruturavam resolvendo problemas acerca do espaço físico e da viabilidade material, elas criavam um circuito organizado de atividades e tarefas comunitárias proposto pela educação de base, o que levou ao estabelecimento de rotinas comuns às comunidades e à introdução de hábitos e costumes até então estranhos à vida local.

\section{Um novo calendário: escola e} civismo

Com a escola, o calendário escolar passou a funcionar como um instrumento de regulação dos ritmos da vida cotidiana do camponês do MEB, ritmo informado por relações com o tempo e por mecanismos diversos que diziam respeito ao ritmo do trabalho agrícola ${ }^{6}$ e ao tempo da religiosidade.

6- Acerca dos ritmos diferenciados da vida de sociedades agrícolas e pré-industriais, ver o capítulo de Edward Palmer Thompson (1984) intitulado Tiempo, disciplina e trabalho. Aqui o trabalhador já aparece captado pelo ritmo da produção agrícola extensiva, porém há que se ter em consideração as representações culturais que levam as comunidades 
Da escola, a comunidade recebeu um rol de informações e um conjunto novo de signos e significados que tinham por pretensão reorganizar o cotidiano, homogeneizando atitudes e representações, uniformizando comportamentos locais em relação aos nacionais e demonstrando preocupações de intervenção sobre o trabalho e sobre o tempo livre do trabalhador/ morador do engenho ${ }^{7}$. Logo de início, a escola apresentou novos signos às comunidades locais, signos estes pertencentes ao universo católico institucionalizado e que vieram alterar práticas costumeiras da população.

0 modo central de comunicação entre as escolas e as centrais radiofônicas era em forma de correspondência escrita - a carta. Nosso estudo privilegiou esse conjunto documental do MEB, o qual reúne cerca de 4.000 cartas das diferentes centrais radiofônicas do Norte e do Nordeste brasileiros, entre 1961 e 1965. Nas cartas enviadas pelos monitores das escolas aos centros radiofônicos, percebemos a introdução de datas comemorativas no universo cultural do camponês, as quais nem sempre assumiam sentido naquele universo cultural, social e religioso.

Em outros casos, práticas e signos locais foram apropriados e normatizados pela escola. Estamos falando diretamente das festas populares e do calendário de festas locais, dimensões do social em que a escola passou a atuar. $\mathrm{Na}$ metodologia de ensino, a promoção de festas e comemorações cívicas assumia o papel de animação popular, ratificando as estratégias de incentivo à mobilização popular. 0 gerenciamento das festas populares era interpretado pelo MEB como momentos de planejamento, decisão, discussão e ação da comunidade em prol de objetivos comuns, o que levou à presença constante da escola na organização dos festejos.

locais a manterem dias santos, feriados e/ou organizarem o tempo livre de acordo com sua cultura.

7 - Iraídes Marques de Freitas Barreiro (1997), em um estudo sobre as campanhas rurais de educação de adultos, reflete acerca da intervenção sobre o lazer do trabalhador rural; de acordo a autora, as formas de lazer das comunidades foram interpretadas como inadequadas, julgandose necessário empreender intervenções de lazer dirigido, como teatro, brincadeiras coletivas, jogos etc.
Em 1962, no mês de maio, as escolas do MEB de Pernambuco, passaram a divulgar o Dia das Mães e a solicitar ações dos monitores como atividades comunitárias em comemoração àquela data - festas, homenagens, encontros, produção de poesias e textos. No mês de agosto e setembro, os programas sugeriram como temática central a pátria e a nação; os professores-locutores, então, incentivaram comemorações do Dia da Pátria, referindo-se ao 7 de Setembro. Nas correspondências, também encontramos menções de monitores com relação às comemorações da Páscoa, das festas juninas e do Dia do Trabalho.

Com exceção das festas dos santos do mês de junho e da festa da Páscoa, todas as outras proposições do MEB surgiram como algo não pertencente aos costumes das comunidades ligadas aos sistemas radiofônicos de Pernambuco.

A festa do Dia das Mães foi apresentada à comunidade como necessária ao reconhecimento de papéis sociais - de esposa e de mãe -, o que enxertava em uma realidade dada concepções externas do papel de mãe e sua função social. Muitas cartas narram a recepção positiva das escolas com relação à comemoração do Dia das Mães e tratam da organização das festividades nas comunidades em prol do tema.

Quanto às comemorações cívicas, podemos dizer que também a receptividade da comunidade e dos alunos da escola foi positiva. As comemorações cívicas do 7 de Setembro e do Dia do Trabalho surgiram como conteúdos da educação moral e cívica associados a uma ideia de nação e a um sentimento de nacionalidade que convocava cada aluno do MEB e cada indivíduo da nação a engajar-se na luta pelo desenvolvimento nacional. Nas cartas, os monitores usaram recorrentemente o termo nação (ou pátria), definindo-o como o conjunto de cidadãos brasileiros. De acordo com o discurso da escola, como cidadãos, todos deveriam assumir o papel de trabalhar e lutar por melhorias sociais, políticas e econômicas do país.

Analfabetismo e cidadania apareceram como termos contraditórios. Tanto nos docu- 
mentos do MEB, quanto nos discursos elaborados pelos monitores, a cidadania foi definida como consciência (conhecimento) dos deveres e direitos e como capacidade de tomar atitudes em prol das transformações necessárias para a mudança social. Caracterizado como indivíduo desprovido dos instrumentos básicos do conhecimento formal e relegado a ações isoladas, individualistas e inconscientes, o analfabeto rural surge representado como não cidadão, carente, portanto, do conjunto de qualidades necessárias ao aprimoramento cultural que o elevaria à categoria de cidadão brasileiro.

A tendência da comunidade ao aceitar a escola foi, desde o início, a de compactuar com a leitura do conjunto de carências dos indivíduos e da comunidade rural. 0 aluno do MEB tendeu a assimilar o discurso nacionalista, compactuando com a ideia do nacional, da pátria e da necessidade de participação política na conquista de direitos de cidadania. A condição de analfabeto era negada em nome da conquista de outra condição que projetasse socialmente os indivíduos e que ampliasse o número de caminhos necessários à superação de problemas de ordem econômica, política, social e cultural.

A noção de civismo da educação de base teve cunho exacerbadamente nacionalista, baseando-se em preceitos de uma cidadania limitada ao conhecimento de direitos e deveres do cidadão e sua atuação cerceada pelas leis. Ainda podemos somar a tudo isso preconceitos acerca do cidadão analfabeto, o qual, sob aquele ponto de vista, não estaria apto a conquistar e/ou exercer autonomamente sua cidadania. No entanto, afirmam-se as múltiplas possibilidades da escola, pois, ao assimilarem em seu discurso e em sua prática cotidiana os preceitos do civismo - realizando a festa do Dia da Pátria e as comemorações do Dia do Trabalho, por exemplo -, as comunidades demonstravam uma apropriação da ideia de cidadania, que assumia um sentido claro de reivindicação e luta na conquista de direitos legítimos: do trabalho, do direito à terra, à saúde e à educação.
Se novos ritmos de vida e novos significados irrompiam sobre práticas culturais seculares, desse movimento resultariam tanto a assimilação dos novos estímulos, quanto a insurreição de costumes e hábitos interligados a funções ritualísticas e costumeiras do indivíduo e/ou da localidade 8 .

A festividade do Dia das Mães coincidia, em maio, com o Mês de Nossa Senhora, período que, nas comunidades rurais do MEB, era comemorado com novenas noturnas realizadas nas casas de seus moradores. A prática recorrente das comunidades e a valorização da figura materna de Nossa Senhora favoreceram a assimilação dos festejos do Dia das Mães, o que tornou possível, em diversas comunidades a organização de festividades nas escolas em homenagem às mães. Por outro lado, nas cartas das escolas, encontramos a manifestação, por parte das monitoras, de reclamações quanto à frequência escolar, que caía abruptamente no mês de maio devido às novenas de Nossa Senhora.

A escola realizava um esforço em implantar um comportamento comum, genérico, que normatizava, inclusive, práticas religiosas, pois, no discurso da escola, as novenas não deveriam inviabilizar as aulas noturnas. Para as comunidades, até então, o tempo dedicado às manifestações religiosas, ao sagrado, não deveria encontrar limitações - quem sabe, nem mesmo a limitação do trabalho -, já que os dias santos e o calendário religioso tendiam a ser guardados rigorosamente pelas comunidades rurais.

Armava-se um conflito entre escola e comunidade caso a escola não conseguisse respeitar, assimilar e/ou ceder a determinados costumes locais. Na medida em que as escolas se instalaram, a tendência foi a convergência de interesses entre comunidade e escola, num ambiente em que algumas resistências individuais e/ou coletivas conviviam com a assimilação de grande parte das proposições da escola.

8 - Thompsom (1984) e Lefebvre (1978) referem-se à capacidade de insurreição da diferença ou de hábitos e costumes seculares diante da imposição de novas práticas sociais, sem desconsiderar a capacidade de assimilação do novo que o campesinato ou as sociedades pré-industriais desenvolvem em suas relações sociais. 
Respostas culturais: resistências cotidianas na escola rural

$\mathrm{Na}$ história dos camponeses do MEB, quando consideramos as práticas e representações sociais, podemos enxergar um conjunto de respostas culturais ${ }^{9}$ que resultam da mediação que os indivíduos e o coletivo realizam em sua realidade material, em que subjazem fatos e objetividades econômicas, sociais, políticas e culturais.

Após identificarmos a intervenção da escola sobre o tempo livre do cotidiano, demarcado, depois da escola, por datas e signos ausentes do universo cultural das comunidades locais, nossa tentativa foi a de investigar mais detalhadamente a intervenção sobre o indivíduo e seus costumes. As cartas trouxeram como tema significativo os conflitos entre a educação de base, seus conteúdos e as práticas costumeiras dos alunos. Ao explorarmos essas vertentes nos documentos do MEB e nas cartas das escolas, encontramos um rol diverso de resistências/ assimilações de comunidades e indivíduos em relação ao projeto educacional.

Os conteúdos dos programas das escolas de rádio dividiam-se, equitativamente, entre ensinamentos da língua e da matemática, e ensinamentos da educação de base. Como componente curricular central, a educação de base gerava temas e reservava a si conteúdos voltados à educação moral e cívica, à educação para o trabalho e às questões da saúde e do corpo, fazendo-se presente nas aulas de alfabetização, de linguagem e de matemática. Por meio da análise de materiais didáticos - cartilha Viver é lutar ${ }^{10}$-, do

9 - 0 termo resposta cultural refere-se à ideia de Edward W. Said (1995) acerca das resistências culturais. Para o autor, as resistências culturais são repostas culturais que grupos, etnias ou classes elaboram a partir de sua historicidade, respondendo a intervenções culturais homogeneizadoras.

10- 0 material didático produzido durante os anos de 1961 e 1962 gerou a organização de uma cartilha intitulada Viver é lutar. A cartilha foi preparada para ser implementada em 1963, quando sofreu processo de apreensão no Rio de Janeiro por parte do governador Carlos Lacerda. Depois de intervenção da cúpula da CNBB junto às autoridades policiais, a cartilha pôde ser utilizada nos sistemas, sofrendo modificações após 0 Golpe de 1964. Tratava-se de um livro de texto que abordava as temáticas citadas. 0 Fundo MEB do CEDIC possui um dossiê elaborado pelo MEB/ CNBB sobre o processo de apreensão da cartilha e sua liberação. conteúdo dos programas educativos, de textos de formação de professores e das cartas, tentamos levantar algumas mensagens centrais da educação de base irradiadas pelos centros radiofônicos diversos. Reconstruindo brevemente as temáticas, identificamos como assuntos prementes:

- a escola, a família e a comunidade como instâncias da organização social;

- o papel social dos indivíduos (que envolvia temas relativos ao comportamento social);

- o trabalho, o sindicato, a cooperativa e seus papéis na organização política do campo;

- a saúde e o corpo;

- a luta por direitos (que incluía a discussão da participação popular e do voto);

- a cultura tratada como elemento de agregação e identidade social na construção da consciência política.

A educação de base definiu a articulação da ação da escola, da família e da comunidade como responsável por mudanças na qualidade de vida das populações. Nas pautas das aulas radiofônicas e em textos didáticos, o tema escola/família/comunidade compunha uma tríade tratada de forma a levar o aluno a discutir seu papel em cada uma dessas instâncias.

Tal tema tocava num problema secular da família rural brasileira: a forte divisão de papéis femininos e masculinos na condução da vida doméstica e na educação dos filhos. Os monitores - em sua maioria, mulheres - não contestavam os conteúdos da EB, mas, nas cartas, apontaram recorrentemente a resistência de jovens e adultos do sexo masculino em assimilar - ou até em ouvir e concordar com - mudanças no papel masculino, seja na família ou na comunidade. Em uma das cartas, a monitora de uma escola do Centro Radiofônico de Educação Rural de Nazaré da Mata (PE) desabafava:

Chã do Rocha, 04 de abril de 1962.

[...] Meus alunos estão entusiasmados, isto

é, a turma B. Tenho nessa turma 15 alunos. Todos já escrevem bem o seu nome 
e copiam com facilidades os exercícios, gostam bastante das aulas de matemática, por que fazem contas e escrevem números. Eles notam logo a diferença na aula de Linguagem, quando trocam de professora. Noto que ainda não há gosto pela aula de Educação de Base, especialmente quando se fala em economia doméstica, higiene da casa, da roupa, coisas que se referem mais a mulher, pois a minha turma é composta de 11 rapazes e 04 moças. [...]

Zilda Aragão. (MEB/PERNAMBUCO, 1961)

Nesse caso, na escola de Zilda, o entendimento dado pela monitora e pelos alunos às aulas de educação de base foi exatamente o mesmo. A monitora ratificou o papel da mulher como responsável pelos afazeres domésticos, justificando o comportamento resistente de seus alunos ao conteúdo proposto.

0 conjunto de conteúdos que tratava do papel dos indivíduos na família e na comunidade tocou em assuntos concernentes ao comportamento social do homem rural - hábitos, costumes e práticas sociais - relacionado a valores comuns, desencadeando, junto aos alunos da escola, resistências de caráter puramente individual, ou, por vezes, coletivo.

A escola do MEB deixou transparecer objetivos de uma ação reformadora do campo cultural do homem rural, tentando impor uma prática cotidiana que acabou por inscrever indivíduos e comunidade em um circuito de apropriação (consumo) de informações, valores e conceitos da cultura, o que resulta das estratégias de instituições objetivando a gestão sobre a sociedade e, principalmente, sobre as particularidades da vida privada. Segundo Henri Lefebvre (1991), há quase que um oportunismo estratégico dessas intervenções globais, que partem das instituições com a finalidade de promover intervenções cotidianas. Demarcadas as devidas diferenças em relação a outros projetos institucionais, as escolas de rádio do MEB, ao proporem a reversão ou extinção de hábitos e costumes, bem como mu- danças de condutas sociais, acabaram por se contrapor a dimensões do vivido, provocando insurgências e subversões.

Os hábitos e costumes mais combatidos nas aulas de educação de base foram o uso de bebidas alcoólicas, o tabagismo e o porte de armas de fogo ou armas brancas, cuja incidência concentrava-se na população masculina da Escola de Rádio. Pelo rádio, as professoras-locutoras argumentavam, insistentemente, quanto aos malefícios das bebidas alcoólicas e do tabaco para a saúde dos trabalhadores rurais, tratando tais hábitos como vícios prejudiciais à saúde e ao comportamento social dos indivíduos.

As cartas depõem o fracasso dos programas junto ao seu público. Muitas delas apresentaram apelos dos monitores, que solicitavam a reprise de programas e de discussões sobre o vício do álcool e o malefício do fogo, expondo suas preocupações diante do desprezo com que os alunos vinham tratando o assunto, na medida em que se perpetuavam as práticas recorrentes tanto na escola, quanto no cotidiano daqueles indivíduos.

Engenho Cardozo, 31 de agosto de 1962. [...] aviso que os alunos da turma B pedem para fazerem sempre ditado, pois eles gostam muito. E também para aumentar os exercícios de matemática. Tem alunos que estão animados para fazer a fossa seca, peço que vocês dêem um lembrete, perguntando quem já começou?

Segue agora perguntas minhas para juntálas com as anteriores. 0 aluno deve fumar na classe? Mesmo escondendo a cabeça em baixo da banca? Será um costume certo andar com a camisa desabotoada? [...] Nada mais a tratar, atenciosamente.

Alice Áurea de Lucena. (MEB/ PERNAMBUCO, 1961)

Nas correspondências, assim como Alice, outras monitoras demonstravam frustrações ao não conseguirem alcançar os objetivos 
propostos pela educação de base, pois seus alunos persistiam em antigos hábitos - fumar, andar de camisa aberta, frequentar a escola com a roupa do trabalho, bebericar entre as refeições ou após a lida -, atitudes que já não cabiam mais dentre os novos hábitos propostos para um bom comportamento social, hábitos estes definidos de acordo com os padrões católicos e escolares, tais como: demonstrar asseio pessoal com o uso de roupas adequadas, cabelo penteado, banho diário, não fumar, não beber, não portar armas, dentre outros.

0 porte de armas (de fogo e brancas) foi, talvez, o hábito mais fortemente combatido nos discursos da educação de base, ao mesmo tempo em que aparece nas cartas como prática arraigada da população masculina, que resiste em aderir ao discurso do MEB sobre a questão.

A monitora Maria Eunice da Silva, da escola São Luis, narrou uma situação em que insistentemente se defrontava com alunos na tentativa de impedi-los de frequentar a escola armados. Não mais podendo controlar a situação, diante do não atendimento de seus apelos, ela resolveu desistir da solicitação, tamanho o desgaste da relação de diálogo no espaço escolar:

Fazenda Jardim, 29 de setembro de 1962. Queridas professoras,

[...] Eu não estou pedindo mais as faca dos meus alunos, porque eu pedia e eles não dava com bom gosto! Então eu deixei de pedir quem tiver a boa vontade de dar dê e quem não, não dê. Tem dois alunos que não quer me obedecer, já fumaro dentro da escola, eu briguei, mais foi mesmo que nada, eles são o José Isidio e o Arlindo Candido. Tenho muitas coisas a dizer, mais só com a nossa vista.

Maria Eunice da Silva. (MEB/PERNAMBUC0, 1961)

Se as orientações dos professores de rádio eram para que os alunos não fumassem e não portassem armas na escola, a ação efetiva para impedir esse tipo de comportamento dava-se cotidianamente na relação monitor/aluno, o que gerava conflitos diretos.

A resistência que se manifestava por meio de respostas comportamentais dos alunos alimentava conflitos diários na escola. Ela era gerada a partir das dimensões do vivido e manifestava-se em atos que reafirmavam práticas contestadas - o gesto de fumar, cuspir, beber, andar de camisa aberta, portar arma -, tornando o cotidiano um lugar de insurgências e subversões, e ratificando o lugar dos gestos e das atitudes como formas de resistência e contestação diante de formas de homogeneização, doutrinação e expropriação política, cultural e econômica das particularidades locais e culturais. Na escola de rádio, emergiram formas de resistência decorrentes de preceitos contraditórios intrínsecos: se a escola exerce ou tenta exercer um papel de integração cultural por meio de códigos e normatizações universalistas, aqui a subversão e a insurgência das particularidades camponesas romperam pretensões do absoluto, demonstrando a fragilidade do monopólio da transmissão cultural relegado, nas sociedades modernas, à instituição escolar.

A persistência do problema - o fumo, a bebida e o porte de arma - nas correspondências de 1961, 1962 e 1963 revela o sentido de tais hábitos na vida social do homem do campo. Fatores internos do modo de vida, que se sedimentam segundo a organização social, política e econômica das comunidades, são o que dá sentido aos hábitos ou costumes. Antonio Candido (2001), tratando dos hábitos e costumes do homem do campo, chamou-nos a atenção para a historicidade dos modos de vida e para os conflitos gerados quando um modo de vida rejeita a intrusão de novos hábitos.

0 porte de arma - de fogo ou branca tinha sentido secular nos costumes do habitante da zona da mata nordestina, representando, dentre outras coisas, a segurança do indivíduo acostumado a caminhar por estradas ermas, acostumado a ouvir, ou mesmo a viver, 
situações de conflitos na terra e no trabalho ${ }^{11}$. Tão arraigado era o costume do porte de arma que, contrariando os preceitos da educação de base e sua função de desenvolvê-la junto à comunidade, um monitor solicitou ao prefeito de sua cidade uma arma de fogo para se dirigir às aulas noturnas. Tal fato reforça nossa ideia sobre o sentido de hábitos e costumes nas resistências políticas e culturais:

Água Branca 30 de maio de 1962.

Faço ciente ao Centro Radiofônico, que a escola Nossa Senhora da Paz, si acha em bom progresso. [...]. Só uma coisa estou achando ruim é a viagem de volta para caza. Onde ensino prá minha caza fica distante. 0 motivo é que, neste tempo de crise e fome, na Sexta-feira passada dia 25 do corrente mês de maio, um malfazejo jogou um tacape na cabeça de um amigo e vizinho, a noite, e bateu com ele no chão. 0 pobre homem saiu rolando pelo chão. Sem sentido e quase que racha a cabeça. Não morreu, porque deu um grande grito e o sujeito correu.

Foi ladrão que foi roubá-lo. Esse acontecimento foi no caminho onde passo toda noite.

Por este motivo estou com receio. Vou falar com o Sr. Prefeito, para ele mi arranjar uma arma de fogo, pois só ando com a alma no corpo,

Felicidades

Venceslau Domingues Luiz. (MEB/ PERNAMBUCO, 1961)

Estamos tratando aqui de atos da vida social do homem do campo - cigarro de palha, camisa aberta, faca ou canivete levado à cintura, os tragos de cachaça em determinados dias da semana - cuja contestação, apresentada pelos conteúdos da educação de base, resultou

11 - A historiografia baseada em dados quantitativos acerca da violência no campo brasileiro apenas viria confirmar o sentido do porte de armas junto à população rural nordestina, principalmente no momento que envolve a atuação das ligas camponesas e a reação dos latifundiários (Cf. MARTINS, 1994). na fabricação de atos que burlavam o discurso externo ou confrontavam-se diretamente com ele. Tendo o cotidiano tornado-se objeto de intervenções, aquilo que é costumeiro acaba por se configurar em ato de resistência, o que não significa que o aluno do MEB resistiu ou negou a escola.

As manifestações explícitas de crítica, resistência e contestação do sentido e da utilidade aparente dos saberes transmitidos surgiram em relação a determinados conteúdos da educação de base, a ponto de, entre abril e maio de 1962, percebermos nas cartas que o Centro Radiofônico de Nazaré dirigiu uma solicitação para que os monitores investigassem acerca da aceitação das aulas de EB na programação do rádio.

De acordo com as respostas registradas pelos monitores, podemos dizer que, de forma geral, os alunos posicionaram-se a favor das aulas de EB, demonstrando interesse por assuntos de saúde, higiene, sindicalização e direitos do trabalho. 0 maior interesse pela educação de base concentrou-se em dois campos: saúde e sindicalização. Assim como afirmam Carlo Ginzburg (1987) e Edward Thompson (1998), que consideraram o sentido de um materialismo elementar próprio da cultura popular - e, no caso de Ginzburg, de camponeses -, pensamos ser procedente falarmos em um sentido fortemente materialista atribuído à preservação do modo de vida e à conquista de direitos pelos camponeses do MEB, que encontraram na educação de base uma forma de resolver problemas presentes no dia a dia das famílias vítimas da ausência de políticas públicas nas regiões rurais de Pernambuco.

No tema da saúde, as correspondências solicitavam informações sobre tratamento de doenças, procedimentos de higiene pessoal, cuidados com crianças, ações de saneamento básico, dentre outros. Os monitores transmitiam aos professores-locutores as dúvidas sobre tratamentos de saúde, manipulação de plantas e confecção de remédios, demonstrando ações da comunidade que, acostumada a resolver seus 
problemas por meio de recursos próprios, buscava apropriar-se de conhecimentos úteis à preservação da saúde diante da situação de abandono em que se encontravam as comunidades.

Nesse contexto, o MEB acabou por assumir o papel de promotor de campanhas de saúde e de saneamento básico, utilizando-se da figura do monitor como um agente educacional que transmitia informações e desencadeava ações coletivas. Detectamos nas cartas o desenvolvimento de campanhas de vacinação, campanha de combate à Namíbia, campanhas antitabagistas e o incentivo à mobilização popular junto ao poder público na conquista de serviços básicos, como construção de fossa seca nas moradias rurais, tratamento da água, e principalmente serviços de eletrificação rural.

Tais ações foram recebidas sempre positivamente, demarcando interesses do homem rural em adquirir conhecimentos novos que ampliassem suas possibilidades autônomas de cuidado com a saúde e acirrando suas demandas pelo direito à saúde, as quais surgiram nas cartas a partir da reivindicação da presença de médicos nas comunidades.

Considerando o sentido de preservação atribuído pelas comunidades aos aspectos centrais de seu modo de vida, bem como os caminhos inventados pelo homem comum na superação de problemas de seu cotidiano, o MEB e a escola de rádio, naquele contexto, propiciaram ao camponês a apropriação de saberes dotados de um sentido de uso que favoreciam as comunidades e sua relação com os preceitos da modernização.

\section{Saberes e práticas camponesas:} festas, leilões e quermesses na escola

0 resgate do processo de instalação da rede de escolas radiofônicas do MEB demonstrou-nos todo um conjunto de potencialidades das comunidades rurais por meio das articulações com o poder local; estas não foram vistas por nós como relações de dependência, mas como articulações com o poder em busca de benefícios para os grupos. Quando a escola chegou nas terras do coronel, submeteu-se a ele, mas também o contestou. Ensinou o homem comum a ler e a fazer contas, para que os patrões não o enganassem tão facilmente na hora do pagamento do barracão.

A escola do MEB alfabetizou e permitiu a conquista do direito ao voto, outro mecanismo de barganha, troca ou contestação usado pelos trabalhadores diante dos donos da terra. Por sua vez, o coronel - usineiro proprietário de engenho - sentia-se seguro: a escola era da igreja, e o padre promovia a ordem e afastava os avanços dos comunistas naquelas paradas.

Realizadas as articulações necessárias para instalação da escola, as comunidades viram-se diante do desafio de, autonomamente, fazê-las funcionar, viabilizando sua perpetuação. 0 desfio de manter a escola demonstrou a dinâmica e as potencialidades da maioria das comunidades em que escolas funcionaram ininterruptamente até o Golpe de 1964.

Para o MEB, a ideia da autopromoção comunitária e da elevação cultural do homem rural justificava a existência do movimento e a urgência de ações reparadoras, uma vez que a leitura feita acerca das comunidades rurais passava pela ideia de que os desníveis social, econômico e político das classes vinham acompanhados de um desnível cultural que deveria ser combatido.

A Cultura popular (movimentos de Cultura Popular) é um fenômeno histórico que tem surgido em sociedades em que se distingue um desnivel cultural entre os diversos grupos que a compõem [...]

Em países insuficientemente desenvolvidos, como o Brasil, o problema aparece mais facilmente em toda a sua dimensão: o desnível cultural proporciona um tipo radical de marginalização que impede a própria comunicação humana entre os diversos grupos sociais [...] as organizações (organizações de Cultura Popular) devem agir no sentido da superação, pela 
sociedade, dos desníveis, entre os diversos grupos sociais que as compõem [...]. (MEB/ NACIONAL, s/d.a)

Apoiado na ideia de desnivel cultural, o MEB subordinava a cultura popular aos paradigmas culturais pensados como superiores, criando uma dicotomia presente na literatura educacional tradicional e conservadora em que o processo de escolarização e/ou o contato com a cultura universal demarcam necessidades de superação de condições tradicionais ou atrasadas. Ao mesmo tempo, contraditoriamente, o Movimento apoiou-se nas positividades das comunidades quanto à sua organização social e à capacidade de articulação política e econômica como formas de viabilização das condições materiais para a instalação e o funcionamento da escola.

Ao analisarmos o conjunto de cartas enviadas ao centro radiofônico do MEB em Pernambuco, pudemos perceber que, em sua quase totalidade, as cartas apresentaram um alto envolvimento da comunidade nas ações de manutenção da escola por diferentes caminhos: algumas escolas optaram pela formação da caixa escolar, arrecadação individual para manutenção das necessidades; outras optaram pelo trabalho comunitário, em que monitores e alunos reuniam esforços para arrecadação financeira por meio de práticas já conhecidas pela comunidade - a festinha, o leilão, a rifa, o bingo.

Em nossa percepção acerca das comunidades, por mais precárias que fossem as ações comunitárias agregadoras, manifestadas em festas, leilões, quermesses e rifas recorrentes no universo popular, estas se constituíram como eixo principal da organização financeira que propiciava a circulação das mercadorias necessárias à manutenção do projeto da escola, como também revelaram o potencial organizativo da comunidade em sua localidade.

As comunidades rurais, desde o período colonial, integraram-se à rede nacional de produção, distribuição e consumo por intermédio de relações ativas com o mercado. Para Shepard Forman (1979), a dinâmica de integração do cam- ponês ao mercado articulou-se à dinâmica do mercado interno e ao consumo da colônia; o lócus da relação eram as feiras, lugar em que se materializava a ação do camponês com o comércio.

No universo das cartas analisadas, percebemos a transposição dos usos e costumes da comunidade na solução de problemas de sobrevivência econômica para o espaço escolar, revelando-se um processo de adaptação de saberes e práticas da comunidade para a escola.

A viabilidade material das escolas radiofônicas dependeu de mecanismos de funcionamento das comunidades rurais, que se alicerçavam em práticas coletivas e associativas antes mesmo das proposições em educação de base. As condições materiais sempre escassas dessa população, principalmente no agreste, levavam à construção de práticas coletivas solidárias bastante remotas que garantiram a sobrevivência das comunidades em território tão inóspito durante séculos.

\section{Considerações finais}

À guisa de conclusão, faz-se necessário, para o entendimento da lógica dos valores e hábitos sociais de um grupo, um posicionamento interpretativo da práxis social desse mesmo grupo social. No que se refere ao camponês, há um conjunto de valores que compõem sua campesinidade - seu modus vivendi -, o que não corresponde simplesmente a um lugar na produção, mas a todo um conjunto moral de valores, ritos e hábitos característicos (WOORTMANN, 1990). 0 mutirão, a feira, as festas de padroeiro que arrecadam fundos para a paróquia, os leilões e as rifas das festas religiosas podem ser encarados como estratégias econômicas das relações sociais de produção dos camponeses. 0 trânsito dessas comunidades por tais ações comunitárias e solidárias deu longevidade à sobrevivência de famílias, grupos, hábitos e valores sociais. Em si, os componentes do desenvolvimento comunitário do MEB não diferiam dessas ações. 
Em síntese, os elementos híbridos da cultura popular permitem-lhe galgar espaços em direção à emancipação por vias próprias e não necessariamente por projetos e proposições externas do projeto institucional modernizador. A formação da ampla rede de escolas radiofônicas do MEB no Nordeste deve ser compreendida em um duplo sentido: se, por um lado, a eficiência de planejamento, a solidez teórica e a práxis engajada fizeram das iniciativas dos agentes do Movimento um elemento fundamental para a construção de um sistema nacional de escolas, por outro, há que se relevar o papel das comunidades, tanto na articulação política em favor da escola, quanto em sua manutenção financeira e em seu funcionamento.

Apesar das intempéries reveladas no conjunto das cartas - os processos de assimilação e resistência aos preceitos do civismo e do higienismo na educação de base; as dificuldades financeiras e materiais gritantes das escolas; a desmobilização social de comunidades -, quando tratamos da organização física e material da rede de escolas radiofônicas, não podemos desprezar elementos associativos dos trabalhadores rurais que explicam, de um ponto de vista não hierarquizante, o papel da cultura popular em projetos emancipatórios. Queremos dizer que, num entendimento da cultura como prática e relações sociais diversas, a cultura popular também se nutriu de impulsos de autonomização, emancipação e por que não? modernização, na medida em que esses projetos estiveram em consonância com a sobrevivência da comunidade em questão.

Desse modo, a escola chegou até os mais distantes rincões do Nordeste, e anônimos trabalhadores rurais moradores das usinas e engenhos de Pernambuco aprenderam a ler e a contar. Camponeses conseguiram seus títulos de eleitores, discutiram ações e estratégias de transformação da vida e de sua condição. Assim, o MEB somou forças à vontade de mudar e de transformar o cotidiano, acrescentou informações, diversificou o universo local. Tudo isso se passou naquele momento em que a grande história tocava os mais distantes lugares com os supostos da modernização, modernização imposta - do centro para o periférico, do Sudeste para o Nordeste, do culto para o popular. 


\section{Referências}

BARREIRO, Iraídes M. de Freitas. Cidadania e educação rural no Brasil: um estudo sobre a CNER (1952-1963). Tese (Doutorado) - Faculdade de Educação, Universidade de São Paulo, São Paulo, 1997.

BOURDIEU, Pierre. Economia das trocas simbólicas. São Paulo: Perspectiva, 1982.

CANCLINI, Néstor. Culturas híbridas. São Paulo: EDUSP, 2000.

CANDIDO, Antonio. Parceiros do Rio Bonito: estudos sobre o caipira paulista e a transformação de seus modos de vida. São Paulo: Duas Cidades, 2001.

FORMAN, Shepard. Camponeses: sua participação no Brasil. Rio de Janeiro: Paz e Terra, 1979.

GINZBURG, Carlo. 0 queijo e os vermes: 0 cotidiano e as idéias de um moleiro perseguido pela inquisição. São Paulo: Cia. das Letras, 1987.

LEFEBVRE, Henri. De lo rural a lo urbano. Barcelona: Edições Península, 1978.

A vida cotidiana e o mundo moderno. São Paulo: Ática, 1991.

0 poder do atraso: ensaios de sociologia da história lenta. São Paulo: Hucitec, 1994.

MEB/NACIONAL. Cultura popular: notas para um roteiro de estudos. Fundo MEB-CEDIC, s/d.a.

Documentos Legais do MEB. Fundo MEB-CEDIC, s/d.b.

. Plano Qüinqüenal do MEB. Fundo MEB-CEDIC, s/d.c.

Relatório Anual. Fundo MEB-CEDIC, 1963.

MEB/PERNAMBUCO. Relatório do $1^{\circ}$ treinamento de monitores. Fundo MEB-CEDIC, 1961.

SAID, Edward W. Cultura e imperialismo. São Paulo: Cia. das Letras, 1995.

THOMPSON, Edward P. Tradicion, revuelta y consciencia de clase: estudios sobre la crisi de la sociedad preindustrial. 2. ed. Barcelona: Editorial Critica, 1984.

. Costumes em comum: estudos sobre cultura popular tradicional. São Paulo: Cia. das Letras, 1998.

WOORTMANN, Klaas. Com parente não se neguceia: campesinato como ordem moral. Anuário Antropológico, Brasilia, 1990.

Recebido em: 10.03.2011

Aprovado em: 05.07.2011

Claudia Moraes de Souza é doutora em História Social e professora da Universidade Estadual Paulista de Marília (UNESP). 